\title{
A simple method to produce fragment seedstock for aquaculture of Pterocladiella capillacea (Gelidiales, Rhodophyta)
}

\author{
Chang Geun Choi ${ }^{1, *}$, Ju Il Lee ${ }^{1}$, Il Ki Hwang ${ }^{2}$ and Sung Min Boo ${ }^{3,4}$ \\ ${ }^{1}$ Department of Ecological Engineering, Pukyong National University, Busan 48513, Korea \\ ${ }^{2}$ Aquaculture Research Department, National Institute of Fishery Science, Gijang 46083, Korea \\ ${ }^{3}$ Department of Biological Sciences, Chungnam National University, Daejeon 34134, Korea \\ ${ }^{4}$ Haejojawon Lab, Daejeon 34028, Korea
}

Raw material of gelidioid red algae yielding high-quality agar has been in short supply due to overharvesting, but in situ farming of gelidioids has not been practical due to their slow growth. To produce vegetative seedstock of a cosmopolitan species, Pterocladiella capillacea, we investigated the number and length of regenerated branches arising from sectioned fragments during 3 weeks of laboratory culture at $10,15,20$, and $25^{\circ} \mathrm{C}$. All sectioned fragments formed axis-like branches mostly from the upper cut edge and stolon-like branches mostly from the lower cut edge, showing a high capacity of regeneration and intrinsic bipolarity. $A t 20^{\circ} \mathrm{C}$, the number of regenerated branches increased to 2.74 \pm 1.29 on the upper cut edge and $4.26 \pm 2.66$ on the lower cut edge. Our study reveals that the use of fragments bearing regenerated branches as seedstock can be a simple method to initiate fast propagation for mass cultivation in the sea or outdoor tank.

Key Words: agar-yielding; aquaculture; fragments seedstock; Gelidiales; Pterocladiella capillacea; sustainable biomass

\section{INTRODUCTION}

Gelidioid red algae are well-known raw materials yielding high-quality bacteriological and pharmaceutical-grade agar and agarose and having valorizing bioactivity (Rhein-Knudsen et al. 2015, Matos et al. 2020). Biocellulose nanocomposites can be developed from the microfibrillar material in the rhizines of Gelidium elegans (Chen et al. 2016). However, the recent shortage of gelidioid biomass due to overharvesting in nature is a major challenge to the future of the high-quality agar and agarose industries (Santos and Melo 2018). Bacterial agarose medium from gelidioids cannot be substituted by carrageenan or other products from red algae (Callaway 2015). There has been recognition of the need for sustainable supplies and investigations of biomass (Akatsuka 1986, Felicini and Perrone 1994, Friedlander 2008, Santos and Melo 2018), but the mass cultivation methods for gelidioids are still not developed.

Pterocladiella capillacea (S. G. Gmelin) Santelices \& Hommersand, long referred to as Pterocladia capillacea (S. G. Gmelin) Bornet, is distributed globally from the Galápagos Islands on the equator to England in the northern hemisphere and New Zealand in the southern hemisphere (Freshwater et al. 1995, Boo et al. 2016). The plants grow by division of a dome-shaped apical cell, and they reach up to $30 \mathrm{~cm}$ in nature (Felicini and Perrone 1994). Although P. capillacea has a Polysiphonia-type life
(9) This is an Open Access article distributed under the terms of the Creative Commons Attribution Non-Commercial License (http://creativecommons.org/licenses/by-nc/3.0/) which permits unrestricted non-commercial use, distribution, and reproduction in any medium, provided the original work is properly cited.
Received June 23, 2021, Accepted November 20, 2021

* Corresponding Author

E-mail: cgchoi@pknu.ac.kr

Tel: +82-51-629-6546, Fax: +82-51-629-6538 


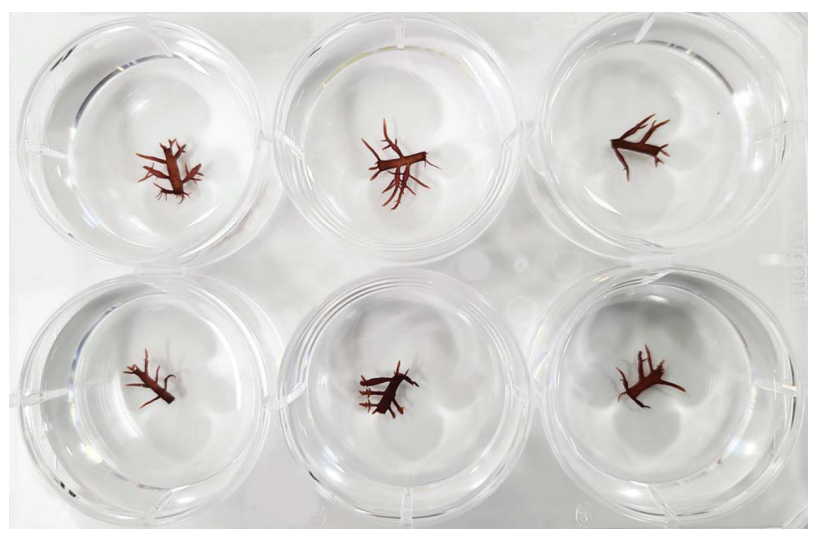

Fig. 1. A six-well culture plate containing a single fragment in each of the wells at $15^{\circ} \mathrm{C}$.

history, asexual tetrasporophytes predominate sexual carposporophytes in the field (Bottalico et al. 2008, Patarra et al. 2020). For example, in Baja California, Mexico, gametophytes occurred solely in January with a very low percentage (less than $0.15 \%$ ) (Servièrse-Zaragoza and Scrosati 2000) and they have been reported to be rare in temperate waters (Felicini and Perrone 1994). Erect plants are mostly annual, while prostrate stolons are perennial, existing for 2-3 years (Felicini and Perrone 1994, Stewart 1968).

P. capillacea may be a suitable species for vegetative propagation due to its high capacity for regeneration from wounded branches (Felicini and Perrone 1994). Many researchers have studied the growth of P. capillacea under various conditions of temperature and irradiance in laboratories, providing valuable data about increasing biomass (Nasr et al. 1966, Friedlander and Zelikovitch 1984, Stewart 1984, Fralick et al. 1990, Macler and Zupan 1991, Yokoya and Oliveira 1992, Felicini et al. 2002, GalOr and Israel 2004, Harb et al. 2018, Patarra et al. 2019). However, their studies have focused mostly on laboratory cultivation. The aquaculture of $P$. capillacea in the sea or outdoor tanks has not made progress due to the poor survival and growth of tetraspore germlings as well as slow growth (Stewart 1984, Friedlander 2008, Santos and Melo 2018). The aim of the present work was to produce vegetative seedstock for mass cultivation of $P$. capillacea. We examined the number and length of regenerated branches arising from both cut edges of sectioned fragments in laboratory culture. This study is the first endeavor to cultivate P. capillacea in Korea, one of the major countries harvesting the species for agar extraction.

\section{MATERIALS AND METHODS}

Samples for growth experiments were collected from March 12-14, 2021, from the intertidal rocky shore at Dongbaek-ri, Gijang on the southeastern coast of Korea. Collections were transported to the laboratory within 20 min and kept in a tank of $10 \mathrm{~L}$ set with running seawater. The plants were cleaned, removing epibionts and surface sediments by a brush and knife under a compound microscope. They were rinsed repeatedly under running seawater for 2 days.

Healthy plants were selected by viewing under a compound microscope, and then clean and young branches were cut to $0.8 \mathrm{~cm}$ long using a medical disposable biopsy punch (Kai Industries Co., Ltd., Saitama, Japan). Growth experiments were carried in a programmable multi-room incubator (JSR, JSMI-04CP; JS Research Inc., Gongju, Korea) with light intensity set at about $27 \mu \mathrm{mol}$ photons $\mathrm{m}^{-2} \mathrm{~s}^{-1}$ and a photoperiod of 10 dark : 14 light. Four temperature conditions were used; 10, 15, 20, and $25^{\circ} \mathrm{C}$, which are approximately similar to seasonal seawater temperatures on Korean coasts (http://iridl.ldeo. columbia.edu/maproom/Global/Ocean-Temp/Monthly_Temp.html). Cultures were kept in a six-well TC-treated multi-well cell culture plate (353046; Falcon, Miami, FL, USA) (Fig. 1). Each well had a single fragment, and a total of 42 sectioned fragments were kept in seven replicates at each of the four temperature options. Provasoli's enriched seawater medium was used (Starr and Zeikus 1993) and the medium was renewed every week. The culture experiments lasted for 3 weeks, and then all cultured fragments were photographed using a Tech Xcam III camera (Techsan Co., Ltd., Seoul, Korea) attached to a compound microscope (SZX10; Olympus, Tokyo, Japan). The length of the longest branch from both cut edges of cultured fragments was measured under the microscope. In addition, the number of branches from both cut sides was counted under the microscope.

Data from 40 fragments were used for statistical analysis except a couple of fragments with abnormal growth. However, 29 fragments were available at $10^{\circ} \mathrm{C}$ because of no growth of other fragments. All data were presented as mean \pm standard error. We assessed the significance of the differences in the length of the longest regenerated branches and the number of regenerated branches on both sides of sectioned fragments among the different temperatures using ANOVAs. The analyses were based on a one-way design among four levels of temperatures as fixed factor. The means were compared using the F-test to determine which of the cultures differed significantly. 
A

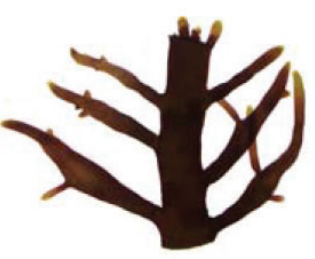

D
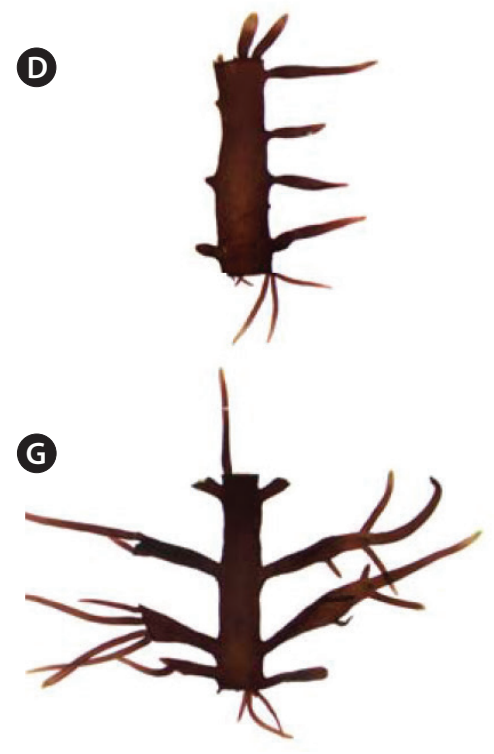

(1)

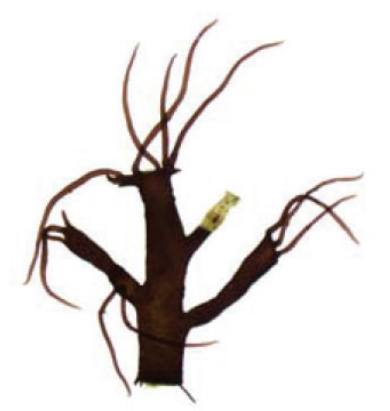

B

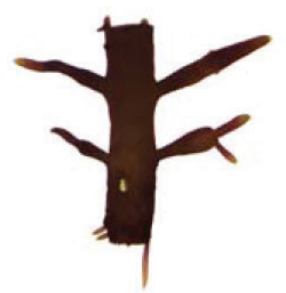

E
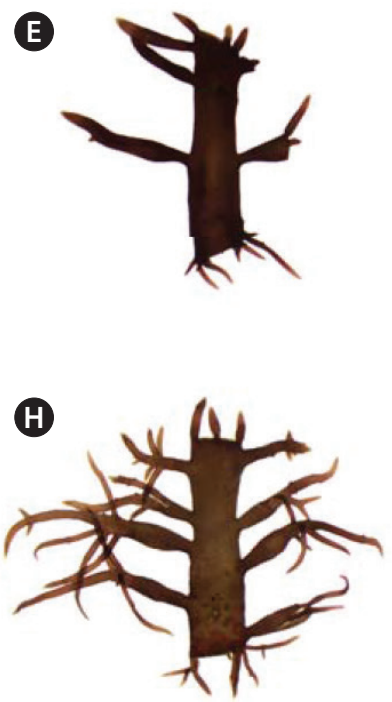

K

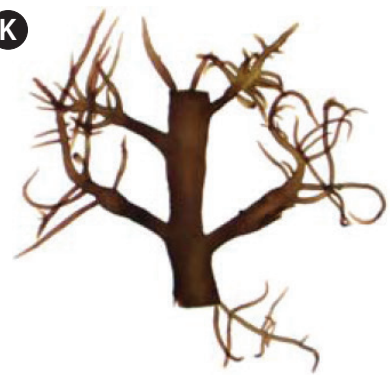

C

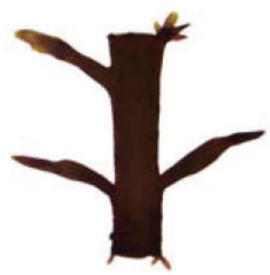

$\boldsymbol{F}$

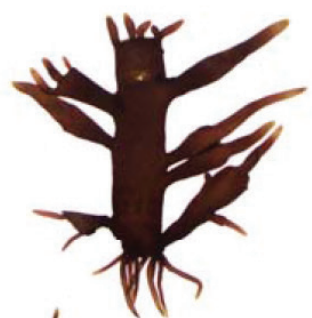

(1)

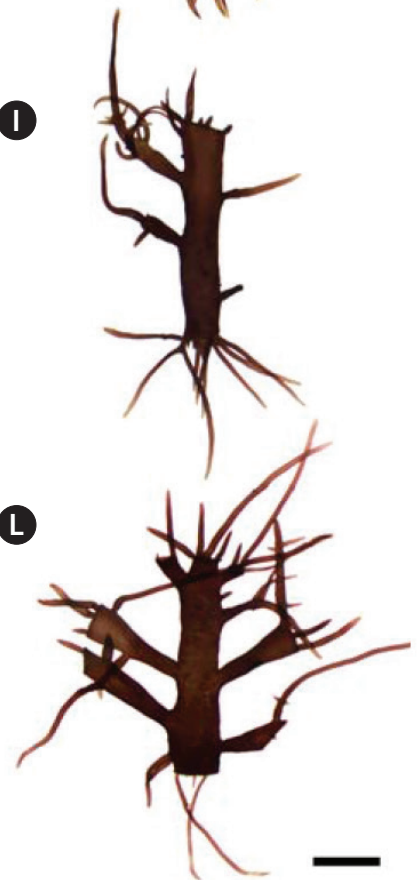

Fig. 2. Various forms of regenerated branches from the upper and lower cut edges of sectioned fragments: fragments cultured at 10 (A-C), 15 (DF), $20(\mathrm{G}-\mathrm{I})$, and $25^{\circ} \mathrm{C}(\mathrm{J}-\mathrm{L})$. Scale bar represents: $2 \mathrm{~mm}$.

When an ANOVA identified a significant difference $(\mathrm{p}<$ 0.05), Tukey's post hoc multiple comparisons were used to identify where the differences occurred. All data analyses were performed using a jamovi 1.8.2 (http://www. jamovi.org).

\section{RESULTS}

In all temperature conditions, sectioned fragments formed axis-like branches from the upper cut edge and stolon-like branches from the lower cut edge. Axis-like branches were mostly compressed and often had blunt tips (Fig. 2A-L). The length of axis-like branches averaged $0.84 \pm 0.05 \mathrm{~mm}$ at $10^{\circ} \mathrm{C}$ cultivation and $1.47 \pm 0.09 \mathrm{~mm}$ at $15^{\circ} \mathrm{C}$. They became branched and long at $20^{\circ} \mathrm{C}$ (Fig. $2 \mathrm{E} \&$ F) and the length increased substantially to $2.93 \pm 1.28$ $\mathrm{mm}$. Their size averaged $3.77 \pm 0.35 \mathrm{~mm}$ at $25^{\circ} \mathrm{C}$. Stolonlike branches were mostly terete and often had acute tips (Fig. 2F). The length of solon-like branches averaged 0.92 $\pm 0.11 \mathrm{~mm}$ at $10^{\circ} \mathrm{C}$ and $1.63 \pm 0.13 \mathrm{~mm}$ at $15^{\circ} \mathrm{C}$. The length increased substantially to $2.93 \pm 0.20 \mathrm{~mm}$ at $20^{\circ} \mathrm{C}$ and $4.15 \pm 0.31 \mathrm{~mm}$ at $25^{\circ} \mathrm{C}$ (Fig. 3 ).

The number of axis-like branches averaged $2.13 \pm 0.24$ 


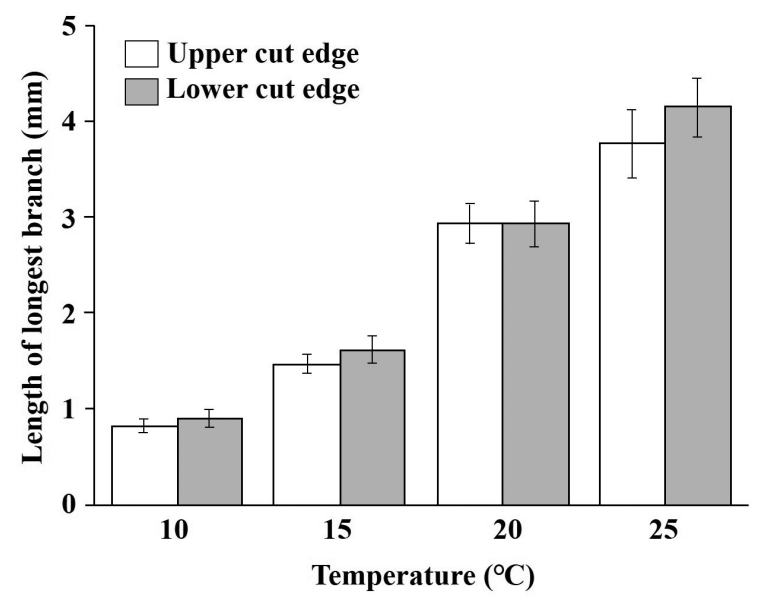

Fig. 3. The Length of longest regenerated branch from the upper and lower cut edges of sectioned fragment at four temperature conditions. Bars were represented as means \pm standard error $(n=40$ fragments except 27 at $10^{\circ} \mathrm{C}$ ).

at $10^{\circ} \mathrm{C}$ and $2.58 \pm 0.21$ at $15^{\circ} \mathrm{C}$. It increased to $2.74 \pm 0.20$ at $20^{\circ} \mathrm{C}$ but decreased to $2.56 \pm 0.21$ at $25^{\circ} \mathrm{C}$ (Fig. 4). The number of stolon-like branches averaged $1.42 \pm 0.18$ at $10^{\circ} \mathrm{C}$. It increased substantially to $4.18 \pm 0.44$ at $15^{\circ} \mathrm{C}$ and $4.26 \pm 0.44$ at $20^{\circ} \mathrm{C}$. However, it decreased to $2.64 \pm 0.22$ at $25^{\circ} \mathrm{C}$ (Fig. 4).

ANOVAs showed significant differences among cultures of sectioned fragments at all temperatures except the number of regenerated branches from the upper cut edge (Table 1). Temperature responses to all growth responses, represented as the length and number of regenerated branches, were significant $(\mathrm{p}<0.001)$. However, the number of regenerated branches from the upper edge was not significant. In addition, growth responses to all temperature options were also significant $(p<0.001)$.

\section{DISCUSSION}

Our study reveals that the upper cut edge of sectioned fragments extends the regeneration area, favoring more axis-like branches rather than a single branch from a single apical cell of the Gelidiales. The lower cut edge also

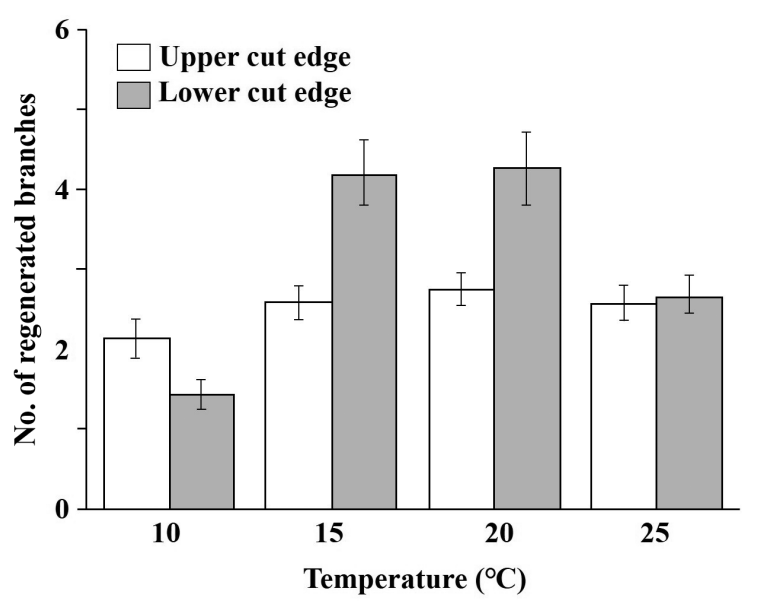

Fig. 4. The number of regenerated branches from the upper and lower cut edges of sectioned fragment at four temperature conditions. Bars were represented as means \pm standard error ( $n=40$ fragments except 27 at $10^{\circ} \mathrm{C}$ ).

produces more stolon-like branches which helps in producing abundant rhizoids for anchoring to the substrata. The results reveal the high regeneration capacity and intrinsic bipolarity of P. capillacea, which is supported by the significant statistical differences in regeneration except the number of regenerated branches from the upper cut edge. The polarity from the sectioned fragments has been reported in previous studies on P. capillacea (Felicini and Perrone 1994, Felicini et al. 2002). Although the growth of fragments has been reported in many previous studies (Stewart 1984, Felicini and Perrone 1994, Gal-Or and Israel 2004), our study is the first on P. capillacea examining the number and length of regenerating branches from both the upper and lower cut edges of sectioned fragments. Axis-like regenerated branches may produce more biomass, while stolon-like branches may have more opportunity to produce holdfasts for anchoring to the substrate. Such fragments likely have a high chance of survival in the sea compared to spores or fragments lacking regenerated branches. A steady supply of fragments with regenerating branches may enable the bottleneck for cultivation of P. capillacea in the sea to be overcome.

Table 1. ANOVA of the length of the longest renewed branch and the number of renewed branches from both cut edges of sectioned fragments at four different temperatures

\begin{tabular}{|c|c|c|c|c|c|}
\hline Variable & Sum of squares & df & Mean square & $\mathbf{F}$ & p-value \\
\hline Length of longest renewed branches from the upper cut edge & 158 & 3 & 52.69 & 33.3 & $<0.001$ \\
\hline Length of longest renewed branches from the lower cut edge & 161 & 3 & 53.70 & 26.4 & $<0.001$ \\
\hline No. of renewed branches from the upper cut edge & 5.55 & 3 & 1.85 & 1.2 & 0.313 \\
\hline No. of renewed branches from the lower cut edge & 116 & 3 & 38.60 & 8.36 & $<0.001$ \\
\hline
\end{tabular}


Our experiments reveal that regeneration of Korean plants was good at $15-25^{\circ} \mathrm{C}$. This is similar to Azorean plants in which growth and branch proliferation occurred at $20-22^{\circ} \mathrm{C}$ (Patarra et al. 2019). Yokoya and Oliveira (1992) reported that Brazilian plants were adapted to either $18^{\circ} \mathrm{C}$ or $22^{\circ} \mathrm{C}$. Felicini et al. (2002) reported that the threshold temperature of distal shoots in fragment cultures of Italian plants was $19-24^{\circ} \mathrm{C}$. However, the optimal growth temperature of $P$. capillacea likely depends on its geographical distribution.

P. capillacea is generally known as a sciophilous species (Gal-Or and Israel 2004, Harb et al. 2018). In our study, relatively low irradiance $\left(27 \mu \mathrm{mol}\right.$ photons $\left.\mathrm{m}^{-2} \mathrm{~s}^{-1}\right)$ induced many regenerating branches at the optimal temperature range. Felicini et al (2002) reported that at $19-24^{\circ} \mathrm{C}, 20-40$ $\mu \mathrm{mol}$ photons $\mathrm{m}^{-2} \mathrm{~s}^{-1}$ induced a compressed axis of Italian plants while $2.5-10 \mu \mathrm{mol}$ photons $\mathrm{m}^{-2} \mathrm{~s}^{-1}$ induced a terete axis, similar to prostrate branches. High irradiances can improve the growth rates of $P$. capillacea, for example at $177 \mu \mathrm{mol}$ photons $\mathrm{m}^{-2} \mathrm{~s}^{-1}$ for Azorean plants (Fralick et al. 1990) and $300 \mu \mathrm{mol}$ photons $\mathrm{m}^{-2} \mathrm{~s}^{-1}$ for Brazilian plants (Harb et al. 2018). However, high irradiances may not favor mass cultivation because they boost the growth of epibionts during culture.

Similar propagation by fragmentation was reported in Gelidium (Fei and Huang 1991, Rodríguez 1996, Nelson and Farr 2003). Fei and Huang (1991) described regeneration of fragments (with section sizes of $2-5 \mathrm{~mm}$ ) of G. elegans Kützing from China (as G. amansii), but it took 30 days to produce regeneration buds of $0.5-1 \mathrm{~mm}$ and 75 days for them to develop into creeping branches of $7 \mathrm{~mm}$. We also found that the growth of new branches from sectioned fragments of G. elegans was very slow (unpublished data). Rodríguez (1996) reported vegetative propagation by fragmentation of G. gonzalezii Rodríguez et al. from Mexico (as G. sclerophyllum), in which growth in length and branch production were favored from medial fragments and rhizoid formation was favored from apical fragments. However, G. crinale subsp. longipes (J. Agardh) W. A. Nelson \& G. H. Boo from New Zealand (as G. longipes) may be a suitable candidate for fragment propagation due to its capacity to regenerate from cut surfaces as well as producing abundant rhizoids for anchoring to the substrate (Nelson and Farr 2003). Vegetative reproduction through fragmentation is not uncommon in nature for red algae such as Dipterocladia, Gigartina, and Hypnea (Buggeln 1981, Cecere et al. 2011, Hwang and Boo 2019).

Our study reveals that 3 weeks' cultivation of sectioned fragments at $15-25^{\circ} \mathrm{C}$ is a time-saving and feasible strat- egy to produce vegetative seedstock for mass cultivation. Fragments bearing regenerated branches can be transferred to outdoor tanks. Further research is needed to evaluate their transfer to rocky shore habitats, as well as their survival rate both in tanks and in situ compared to that of spores released in nature.

In addition to need for sustainable biomass for agar industries, there is considerable interest globally in the issue of coastal restoration and ocean afforestration, including the roles of subcanopy taxa (Tait and Schiel 2018). The development of appropriate seedstock and nursey techniques are essential for progress to meet these targets. We are continuing research on the use of sectioned fragments with regenerated branches for cultivation in ourdoor tanks or in the sea. Further methodological improvements, using sectioned fragments as seedstock, have potential to support agar industries in the near future, and may be able to be applied to other Gelidiales species that are low in regeneration capacity but high in agar quality.

\section{ACKNOWLEDGEMENTS}

We appreciate Wendy Nelson for improving the readability of our paper. This work was supported by a research grant of Pukyong National University (2021).

\section{CONFLICTS OF INTEREST}

The authors declare that they have no potential conflicts of interest.

\section{REFERENCES}

Akatsuka, I. 1986. Japanese Gelidiales (Rhodophyta), especially Gelidium. Oceanogr. Mar. Biol. Ann. Rev. 24:171-263.

Boo, G. H., Hughey, J. R., Miller, K. A. \& Boo, S. M. 2016. Mitogenomes from type specimens, a genotyping tool for morphologically simple species: ten genomes of agarproducing red algae. Sci. Rep. 6:e35337.

Bottalico, A., Delle Foglie, C. I. \& Fanelli, M. 2008. Growth and reproductive phenology of Pterocladiella capillacea (Rhodophyta: Gelidiales) from the southern Adriatic Sea. Bot. Mar. 51:124-131.

Buggeln, R. G. 1981. Morphogenesis and growth regulators. In Lobban, C. S. \& Wynne, M. J. (Eds.) The Biology of Seaweeds. Blackwell Scientific Publications, Oxford, pp. 
$627-660$.

Callaway, E. 2015. Lab staple agar hit by seaweed shortage. Nature 528:171-172.

Cecere, E., Petrocelli, A. \& Veraque, M. 2011. Vegetative reproduction by multicellular propagules in Rhodophyta: an overview. Mar. Ecol. 32:419-437.

Chen, Y. W., Lee, H. V., Juan, J. C. \& Phang, S. -M. 2016. Production of new cellulose nanomaterial from red algae marine biomass Gelidium elegans. Carbohydr. Polym. 151:1210-1219.

Fei, X. G. \& Huang, L. J. 1991. Artificial sporeling and field cultivation of Gelidium in China. Hydrobiologia 221: $119-124$

Felicini, G. P., Bottalico, A. \& Fanelli, M. 2002. Morphogenesis in Pterocladiella capillacea (Rhodophyta, Gelidiales): bud differentiation in relation to irradiance-temperature combinations. Plant Biosyst. 136:261-267.

Felicini, G. P. \& Perrone, C. 1994. Pterocladia. In Akatsuka, I. (Ed.) Biology of Economic Algae. SPB Academic Publishing, The Hague, pp. 283-344.

Fralick, R. A., Baldwin, H. P., Neto, A. I. \& Hehre, E. J. 1990. Physiological responses of Pterocladia and Gelidium (Gelidiales, Rhodophyta) from the Azores, Portugal. Hydrobiologia 204-205:479-482.

Freshwater, D. W., Fredericq, S. \& Hommersand, M. H. 1995. A molecular phylogeny of the Gelidiales (Rhodophyta) based on analysis of plastid $r b c \mathrm{~L}$ nucleotide sequences. J. Phycol. 31:616-632.

Friedlander, M. 2008. Advances in cultivation of the Gelidiales. J. Appl. Phycol. 20:451-456.

Friedlander, M. \& Zelikovitch, N. 1984. Growth rates, phycocolloid yield and quality of the red seaweeds, Gracilaria sp., Pterocladia capillacea, Hypnea musciformis, and Hypnea cornuta, in field studies in Israel. Aquaculture 40:57-66.

Gal-Or, S. \& Israel, A. 2004. Growth responses of Pterocladiella capillacea (Rhodophyta) in laboratory and outdoor cultivation. J. Appl. Phycol. 16:195-202.

Harb, T. B., Nardelli, A. \& Chow, F. 2018. Physiological responses of Pterocladiella capillacea (Rhodophyta, Gelidiales) under two light intensities. Photosynthetica 56:1093-1106.

Hwang, I. K. \& Boo, G. H. 2019. Vegetative reproduction and phylogeny of a new subtidal alga from Korea: Dipterocladia yongdeokkoi sp. nov. (Ceramiales, Rhodophyta). Phycologia 58:26-35.

Macler, B. A. \& Zupan, J. R. 1991. Physiological basis for the cultivation of the Gelidiaceae. Hydrobiologia 221:83-90.

Matos, J., Gomes, A., Cardoso, C., Afonso, C., Campos, A. M., Gomes, R., Falé, P., Delgado, I., Coelho, I., Castanheira,
I. \& Bandarra, N. M. 2020. Commercial red seaweed in Portugal (Gelidium sesquipedale and Pterocladiella capillacea, Florideophyceae): going beyond a singlepurpose product approach by valorizing bioactivity. Thalassas 36:213-224.

Nasr, A. H., Mohsen, A. F. \& Bekheet, I. A. 1966. Effect of salinity and temperature variations on Pterocladia capillacea. Hydrobiologia 27:395-400.

Nelson, W. A. \& Farr, T. J. 2003. Field and morphological observations of Gelidium longipes (Gelidiales, Rhodophyta), a rare endemic red alga from northern New Zealand. N. Z. J. Bot. 41:707-713.

Patarra, R. F., Iha, C., Pereira, L. \& Neto, A. I. 2020. Concise review of the species Pterocladiella capillacea (S.G. Gmelin) Santelices \& Hommersand. J. Appl. Phycol. 32:787-808.

Patarra, R. F., Lloveras, A. A., Carreiro, A. S., Abreu, M. H., Buschmann, A. H. \& Neto, A. I. 2019. Short term effects of irradiance on the growth of Pterocladiella capillacea (Gelidiales, Rhodophyta). Arquipelago Life Mar. Sci. 36:85-94.

Rhein-Knudsen, N., Ale, M. T. \& Meyer, A. S. 2015. Seaweed hydrocolloid production: an update on enzyme assisted extraction and modification technologies. Mar. Drugs 13:3340-3359.

Rodríguez, D. 1996. Vegetative propagation by fragmentation of Gelidium sclerophyllum (Gelidiales, Rhodophyta). Hydrobiologia 326:361-365.

Santos, R. \& Melo, R. A. 2018. Global shortage of technical agars: back to basics (resource management). J. Appl. Phycol. 30:2463-2473.

Servièrse-Zaragoza, E. \& Scrosati, R. 2000. Reproductive phenology of Pterocladiella capillacea (Rhodophyta: Gelidiales) from Southern Baja California, Mexico. Pac. Sci. 56:285-290.

Starr, R. C. \& Zeikus, J. A. 1993. UTEX: the culture collection of algae at the University of Texas at Austin: 1993 list of cultures. J. Phycol. 29(Suppl):1-106.

Stewart, J. G. 1968. Morphological variation in Pterocladia pyramidale. J. Phycol. 4:76-84.

Stewart, J. G. 1984. Vegetative growth rates of Pterocladia capillacea (Gelidiaceae, Rhodophyta). Bot. Mar. 27:85-94.

Tait, L. W. \& Schiel, D. R. 2018. Ecophysiology of layered macroalgal assemblages: importance of subcanophy species biodiversity in buffering primary production. Front. Mar. Sci. 5:444.

Yokoya, N. S. \& Oliveira, E. C. 1992. Temperature responses of economically important red algae and their potential for mariculture in Brazilian waters. J. Appl. Phycol. 4:339-345. 